\section{Cannabis y el cerebro adolescente}

\section{Cannabis and the teenager's brain}

\section{Señor Editor:}

La legalización del uso medicinal y recreativo de la marihuana (Cannabis sativa) es un tema de controversia mundial. Un artículo en Nature Reviews Neuroscience ${ }^{1}$ destaca que el uso de Cannabis es cada vez más importante para la medicina moderna, especialmente en el tratamiento del dolor y de trastornos motores. Sin embargo, su uso más extendido es «recreacional» debido a las sensaciones psicológicas y físicas placenteras que refieren quienes la consumen -a menudo incluyendo euforia, risa, hambre y mayor percepción auditiva y visual $^{1}$. No obstante, entre sus consecuencias adversas se reportan adicción ${ }^{1}$, alteraciones neuroendocrinas ${ }^{2}$, deterioro cognitivo ${ }^{1}$ y riesgo de psicosis ${ }^{1,3}$. Lo anterior es relevante ya que muchos consumidores de Cannabis son adolescentes ${ }^{3,4}$. Considerando los efectos relacionados con la remodelación de circuitos cerebrales que neurotransmisores, hormonas y otros compuestos ejercen durante pubertad y adolescencia ${ }^{5}$, cabe preguntarse: ¿el consumo de Cannabis afecta el desarrollo del cerebro adolescente?, ¿es comparable el efecto de su consumo entre adolescentes y adultos? En virtud de lo anterior, en esta carta se discute el efecto de Cannabis sobre el cerebro adolescente.

Desde un punto de vista endocrino, la marihuana alteraría los niveles de hormonas reproductivas. Un estudio clásico en The New England Journal of Medicine $^{2}$ informó que en varones su consumo frecuente se relacionaba con niveles de testosterona más bajos respecto a quienes nunca consumieron ${ }^{2}$. Estos efectos endocrino-reproductivos son relevantes en adolescentes que consumen Cannabis; pues tales eventos que activan el eje hipotalámico-hipofisario-gonadal se dan en la pubertad y se consolidan en la adolescencia ${ }^{5}$. La exposición crónica a Cannabis durante la adolescencia tiene efectos en algunas zonas cerebrales (e.g., corteza prefrontal, núcleo accumbens y área tegmental ventral $)^{1}$, viéndose afectados procesos relacionados con la recompensa y la cognición ${ }^{1}$ (Figura 1). Estos efectos son preocupantes, más aun considerando que el desarrollo neurofisiológico y conductual ya es particularmente complejo en adolescentes ${ }^{5}$. Se sabe que durante pubertad y adolescencia diversos compuestos participan en fenómenos organizacionales (e.g., mielinización,

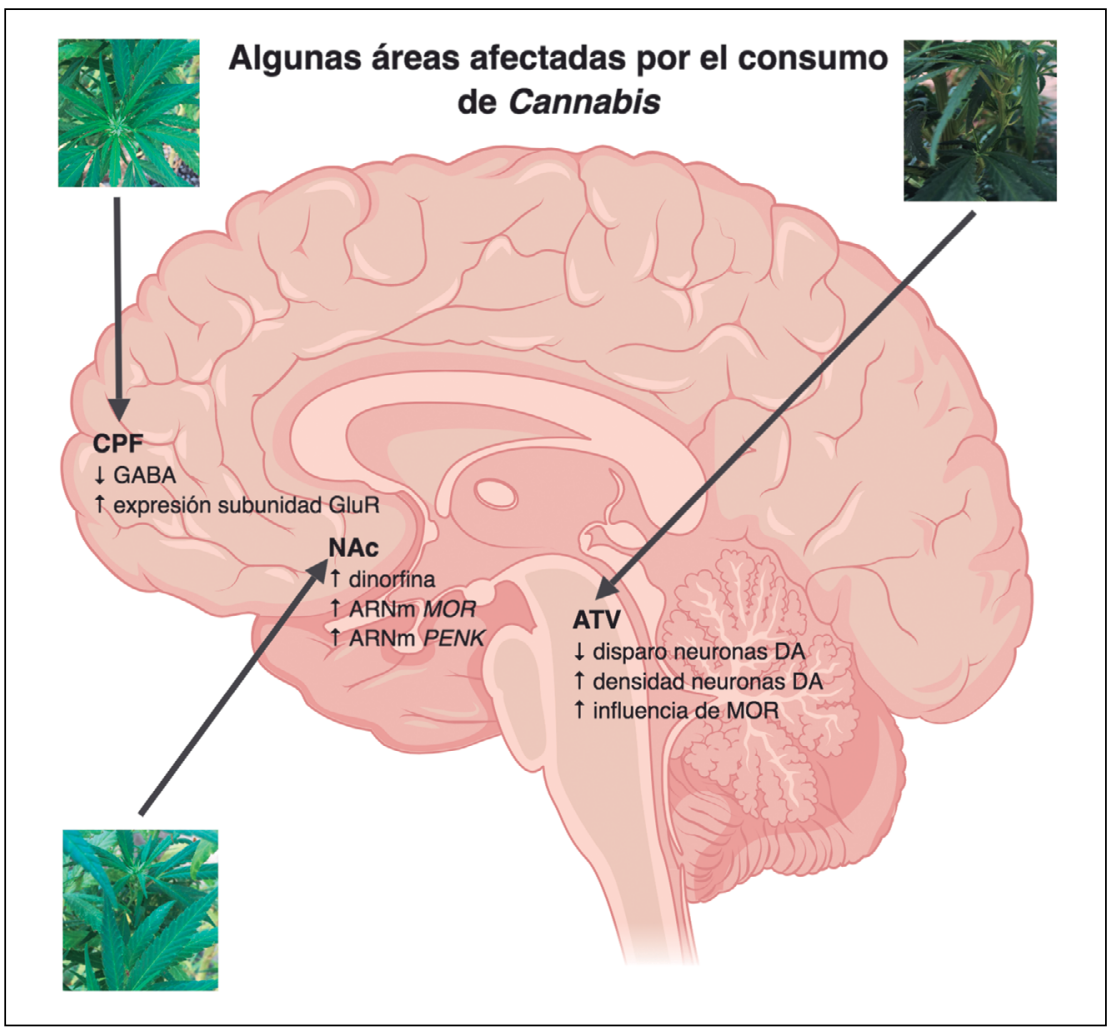

Figura 1. Efectos de exposición crónica a Cannabis durante la adolescencia en áreas cuyos circuitos neuronales están relacionados con recompensa y cognición'. CPF: corteza prefrontal; GABA: ácido gamma-amino butírico; GluR: receptor de glutamato; NAc: núcleo accumbens; MOR: receptor opioide mu; PENK: proencefalina; ATV: área tegmental ventral; DA: dopaminérgicas. 
poda neuronal, apoptosis, remodelación dendrítica y cambios epigenéticos) ${ }^{5}$, configurando estructuralmente algunos circuitos cerebrales 5 . En la adultez esto permitirá la manifestación de comportamientos específicos como respuestas a los compuestos que ahora activan dichos circuitos ${ }^{5}$. La adolescencia es, entonces, una «ventana organizacional crítica» para que el cerebro se desarrolle adecuadamente ${ }^{5}$, ventana que puede ser afectada por Cannabis y otras drogas.

El consumo de marihuana en adolescentes tendría como «puerta de entrada» el consumo de tabaco (nicotina) $)^{6}$. Esta «Hipótesis de la Puerta de Entrada» -desarrollada por la epidemióloga Denise Kandel junto al neuropsiquiatra Eric Kandel, Premio Nobel de Medicina y Fisiología- plantea que los jóvenes se involucran en las drogas en etapas ${ }^{6}$, i.e., existiría una secuencia de desarrollo del consumo bien definida que comienza con una droga legal, para derivar en drogas ilegales ${ }^{6}$. Bajo este supuesto, el consumo de tabaco o alcohol precedería al de marihuana que, a su vez, precedería al consumo de drogas duras ${ }^{6}$. ¿Cuál es la relación entre consumo de drogas y depresión entre adolescentes? Una investigación efectuada en Chile ${ }^{4}$ encontró que a mayor consumo de droga (tabaco, alcohol o marihuana), mayor es la probabilidad de observar síntomas depresivos en adolescentes y que esta asociación se hace más pronunciada a mayor intensidad de la sintomatología depresiva ${ }^{4}$. Más aún, recientemente en Addiction ${ }^{3}$ se ha demostrado que existen asociaciones entre el consumo y la frecuencia del consumo de Cannabis y síntomas psicóticos y depresivos en adolescencia tardía y edad adulta $^{3}$; los cuales, además, se extienden durante la adultez ${ }^{3}$.

Ciertamente el consumo de Cannabis puede afectar el desarrollo cerebral de los adolescentes. Esto, pues durante pubertad y adolescencia el cerebro experimenta una "ventana de plasticidad crítica ${ }^{5}$ que puede ser afectada por sustancias endógenas y exógenas ${ }^{5}$, con consecuencias que pueden manifestarse en la adultez ${ }^{3}$. Por tanto, no deben relativizarse ni desestimarse los efectos que tiene su consumo entre adolescentes, ni tampoco compararse con aquellos observados en adultos. Es necesario que las políticas públicas en salud y educación prevengan el consumo de Cannabis y otras drogas en adolescentes, generando un aprendizaje en ellos mediante la adquisición de hábitos y estilos de vida saludables que perduren toda la vida.
Agradecimientos: Al XII Concurso de Investigación en Docencia Universitaria (IDU 12009, UBO) y $2^{\circ}$ Concurso Proyectos Internos de Investigación 2018 UBO. A la Ing. Laura Collao por su apoyo con la figura.

Manuel E. Cortés ${ }^{1,2, a}$, Yanara Bernal ${ }^{3,4, b}$, Renán Orellana ${ }^{1,5, c}$

${ }^{1}$ Departamento de Ciencias Químicas y Biológicas, Universidad Bernardo O'Higgins (UBO).

${ }^{2}$ Centro de Investigación en Educación, UBO.

${ }^{3}$ Tesista, Magister en Ciencias Químico Biológicas, UBO. ${ }^{4}$ Reproductive Health Research Institute.

${ }^{5}$ Departamento de Ginecología, Facultad de Medicina, Pontificia Universidad Católica de Chile. ${ }^{a}$ Biólogo, Ingeniero en Prevención de Riesgos (registrado en Seremi Salud-RM), MBA, MSc, PhD.

${ }^{b}$ Enfermera.

'Doctor en Ciencias Biológicas mención Ciencias Fisiológicas.

\section{Referencias}

1. Curran HV, Freeman TP, Mokrysz C, Lewis DA, Morgan CJA, Parsons LH. Keep off the grass? Cannabis, cognition and addiction. Nat Rev Neurosci 2016; 17 (5): 293-306.

2. Kolodny RC, Masters WH, Kolodner RM, Toro G. Depression of plasma testosterone levels after chronic intensive marihuana use. N Engl J Med 1974; 290 (16): 872-4.

3. Leadbeater BJ, Ames ME, Linden-Carmichael AN. Age-varying effects of Cannabis use frequency and disorder on symptoms of psychosis, depression and anxiety in adolescents and adults. Addiction 2019; 114 (2): 278-93.

4. Rojas G, Gaete J, Guajardo V, Martínez V, Barroihlet S, Meneses J, et al. Consumo de sustancias y síntomas depresivos en escolares de liceos municipales de Santiago. Rev Med Chile 2012; 140 (2): 184-91.

5. Vigil P, Orellana RF, Cortés ME, Molina CT, Switzer BE, Klaus $\mathrm{H}$. Endocrine modulation of the adolescent brain: A review. J Pediatr Adolesc Gynecol 2011; 24 (6): 330-7.

6. Kandel ER, Kandel DB. A molecular basis for nicotine as a gateway drug. N Engl J Med 2014; 371 (10): 932-43. 